\title{
Exploring mHealth Participation for Emergency Response Communities
}

\author{
David G. Schwartz \\ Graduate School of Business Administration \\ Bar-Ilan University \\ Ramat-Gan, Israel \\ david.schwartz@biu.ac.il
}

\author{
Abdelouahab Bellou \\ Harvard Medical School \\ Beth Israel Deaconness Medical Center \\ Boston, MA, USA
Luis Garcia-Castrillo
Emergency Dept. Servicio Cantabro de Salud
Hospital Universitario Marques de Valdecilla
Cantabria, Spain

\section{Antonella Muraro}

Food Allergy Referral Centre Veneto Region

Padua General University Hospital

Padua, Italy

\author{
Nikolaos Papadopoulos \\ Center for Pediatrics and Child Health \\ Institute of Human Development \\ The University of Manchester \\ Manchester, United Kingdom \\ and \\ Department of Allergy \\ University of Athens \\ Athens, Greece
}

\section{Abstract}

We explore the challenges of participation by members of emergency response communities who share a similar condition and treatment, and are called upon to participate in emergency events experienced by fellow members. Smartphones and location-based social networking technologies present an opportunity to re-engineer certain aspects of emergency medical response. Life-saving prescription medication extended in an emergency by one individual to another occurs on a micro level, anecdotally documented. We illustrate the issues and our approach through the example of an app to support patients prone to anaphylaxis and prescribed to carry epinephrine auto-injectors. We address unique participation challenges in an mHealth environment in which interventions are primarily short-term interactions which require clear and precise decision-making and constant tracking of potential participants in responding to an emergency medical event. The conflicting effects of diffused responsibility and shared identity are identified as key factors in modelling participation.

Keywords: mHealth; participation; smartphones; chronic disease; emergency medical response; social networking; anaphylaxis; EMS; shared identity; diffused responsibility.

\section{Introduction}

Mobile healthcare applications (mHealth apps) have ushered in a new age of participatory medicine. Developments in mHealth have led to a sharp increase in the availability of apps supporting medically motivated real-world interaction between app users, leading to 
potentially significant changes in healthcare delivery (Anderson \& Emmerton, 2015; Malvey \& Slovensky, 2014; Swan, 2009). Of particular interest is the category of mHealth apps which facilitate spontaneous communication between stakeholders in response to an emergency event. Smartphone applications can support the connection of app users to real-world medical emergency events and are being studied in diverse situations such as the mapping and response-use of AEDs (Automatic Electronic Defibrillators) (Folke et al., 2009; Merchant et al., 2013; Peberdy et al., 2006; Rea, Blackwood, Damon, Phelps, \& Eisenberg, 2011; Sakai et al., 2011), volunteer emergency response (Cappato et al., 2006; Elsner, Meisen, Ewert, Schilberg, \& Jeschke, 2014; Elsner, Meisen, Thelen, Schilberg, \& Jeschke, 2013; Elsner, Schneiders, Haberstroh, Schilberg, \& Jeschke, 2013; Groh et al., 2007; Marshall et al., 2006), the physical proximity of diabetes patients (D. Johnson, 2014) in need of glucose or monitors, and Emergency Response Communities (ERC) for anaphylaxis events (Schwartz, Bellou, Garcia-Castrillo, Muraro \& Papadopoulos, 2014). Such systems have the potential to enable a new form of emergency medical response in which the social network-based connection between individuals creates a lay-layer of support which can augment or potentially modify current forms of EMS (Emergency Medical Services). Like most interactions between patients and EMS, many of these apps rely on fleeting one-off interactions between patient and a responding participant, which is quite different from the ongoing long-term relationships fostered between patients and their caregivers in most forms of participatory medicine. In this paper we investigate the nature of this new form of participation against the backdrop of an Emergency Response Community designed to support allergy-sufferers in the event of an anaphylactic reaction.

Participatory medicine envisions enhanced communication between all stakeholders to collaborate and contribute towards patients' wellbeing (Ahern, Woods, Lightowler, Finley, \& Houston, 2011; Dyson, 2009). These stakeholders are generally viewed in terms of the standard medical ecosystem of the individual patient - i.e. the patient's family, caregivers, physicians, third-party HMOs and institutions where the patient is treated and extend beyond the individual to include advocacy groups, clinical scientists, and regulatory authorities (De Silva, Burstein, Stranieri, Williams, \& Rinehart, 2013). Much of the work in this important area views community participation as the measure of a long-term ongoing relationship in which all stakeholders maintain various levels of involvement and has focused on ways to enhance our understanding of interactions between people (McKemmish et al., 2012). The primary forms of participation are considered decision making, information gathering, information sharing between stakeholders, and condition monitoring. This type of deep and long-term participatory relationship in support of Patient Centred Care and $\mathrm{P} 4$ medicine (predictive, preventive, personalized and participatory) is being applied in areas ranging from the management of Autism Spectrum Disorder (De Silva et al., 2013) to family-centric genomic sequencing and the digitization of medicine (Hood \& Flores, 2012). Among the key aspects of participatory medicine for people is knowing when and how to call on friends, family and other social networks for help and advice and have access to them (Smith, Graedon, \& Graedon, 2016). It is these latter aspects - the immediate short-term need for intervention - that we focus on in studying ERC and the participatory behaviour of community members in an emergency event.

Participatory health information systems (PHIS) serve a primary role in enabling these interactions. Emergency response apps and their underlying PHIS necessitate new considerations to the study of participation. This is due to (a) the fundamental reciprocity built-in to such apps in which all community members can equally become one who alerts or one who responds and (b) the lack of any form of social interaction outside of the emergency event. Contrary to what is found in most social networking communication, an alert is not communication directed at counterparts chosen by the member, but rather is sent to the full subset of members available to respond at that time. Thus the potential participants in any given medical event are never known in advance and participation is not dependent on the relationship factors that dominate the study of participatory medicine. Members of such communities may in fact maintain relative anonymity and inactive yet latent links with all 
other members. This results in participation models, user characteristics, and participation behaviours unlike those traditionally studied in participatory medicine.

To illustrate and analyse the nature of these ties and serve as a backdrop to our discussion we present an app in support of an ERC for allergy patients at risk of anaphylaxis events. The information system, which integrates patient, physician and EMS participation, advanced matching of prescription medication, and location-based social networking, is being initially focused on anaphylaxis with broad potential for other chronic conditions. The ERC system and anaphylaxis app design emerged by following a soft systems methodology (Checkland, 2000) of modelling workflow and information flow (Durugbo, Tiwari, \& Alcock, 2013; Hibberd \& Evatt, 2004; Unertl, Weinger, Johnson, \& Lorenzi, 2009). To facilitate this process we engaged with a pool of 18 medical professionals across the fields of Emergency Medicine (8), Allergy and Clinical Immunology (4), Pharmacology (4) and Public Health (4).

\subsection{Anaphylaxis as an illustrative case}

Anaphylaxis is a severe, potentially fatal, systemic allergic or hypersensitivity reaction of rapid onset. It may trigger life-threatening cardiopulmonary compromise, often with skin and mucosal changes such as urticaria and angioedema. With the onset of anaphylaxis an immediate intramuscular (im) adrenaline injection is the first-line of treatment and can be lifesaving and it has been noted that there are no absolute contraindications to the prescription and utilization of self-injectable adrenaline (Song, Worm, \& Lieberman, 2014).Many chronic conditions involve patients maintaining a long-term prescription and current supply of medication. Certain conditions, including asthma, acute allergies, and diabetes (glycaemic control), have significant global populations being treated using a narrow set of medications. In many cases the aforementioned conditions generally require that the patient carry one or more doses of medication on their person at all times. The combination of stable prescriptions, narrow medical regimens, and high availability presents a common basis for community formation (Simons \& World Allergy Organization, 2009; "Standards of Medical Care in Diabetes--2012," 2011, US Department of Health and Human Services, 2007). This type of community formulation goes beyond the membership characteristics commonly considered for Online Health Communities (OHC) (van der Eijk et al., 2013) even when such communities are 'closed' and monitored by a community manager.

Adherence by chronic patients to medical regimens is recognized to be dismally low (Sabaté, 2003). With anaphylaxis in particular, it has been noted that many patients who have been prescribed epinephrine auto-injectors, because of a previous anaphylactic attack, do not carry them with studies showing that $<30 \%$ of these patients carried it at all times (Johnson \& Parker, 2006; Kastner, Harada, \& Waserman, 2010; Song et al., 2014). There are few studies on anaphylaxis management in pre hospital settings. In the USA, the number of 911 calls for anaphylaxis is $0.4-0.9 \%$ of all calls (Maio et al., 1999). Chung et al (2014) showed that in an urban Canadian centre from 481 identified allergy-related case records managed in the pre hospital setting, 136 (28\%) met guideline criteria for anaphylaxis and 56\% were considered high acuity level by the dispatch centre. Only $25 \%$ of patients self-administered epinephrine and $36 \%$ of patients received epinephrine by paramedics. Overall, $44 \%$ of patients received epinephrine prior the arrival of EMS team. It appears that paramedics are not comfortable to use epinephrine likely because of pre existing misconceptions regarding epinephrine.

Epinephrine is the essential medication for the treatment of anaphylaxis and epinephrine autoinjectors are universally recommended as first-aid treatment for anaphylaxis occurring in community settings. Despite this, significant delay in epinephrine administration (i.e., $\geq 5$ min) was also found to be an important gap in anaphylaxis management (Bilò et al., 2016; Kastner et al., 2010). The onset of anaphylaxis can be sudden however it is generally recognized (Song et al., 2014) that there is sufficient time and awareness on the part of the patient to initiate use of an epinephrine auto-injector should one be available. During this same time period a patient would be capable of initiating emergency use of an ERC app to summon help. 


\section{Social Networking, Mobile Telephones, and Health Care Delivery}

It is recognized that social networking has the potential to change patterns of health inequalities and access to health care, alter the stability of health care provision and lead to a reformulation of the role of health professionals (Griffiths et al., 2012). The study of mobile telephony and social networking's impacts on health care delivery is widespread but has been limited to the behavioural effects of information sharing (Shrank, Choudhry, Swanton, \& et al, 2011), patient monitoring (Weitzman, Kelemen, Quinn, Eggleston, \& Mandl, 2013), intervention and behaviour modification (Gold et al., 2012), and peer influencing, with a more recent focus on the day-to-day management of chronic conditions (Parmanto et al., 2013).

A comprehensive meta-analysis of mobile-phone health interventions (Klasnja \& Pratt, 2012) analyses 73 studies to elicit five health intervention strategies: Tracking health information; Involving the healthcare team; Leveraging social influence; Increasing accessibility of health information; Utilizing entertainment. Notably, neither the five derived categories nor any of the underlying studies contemplate a mobile-based intervention strategy that involves one patient actually bringing a critical dose to another patient in distress. A comprehensive review of mobile health applications is presented by Martinez-Perez et al. (Martínez-Pérez, de la Torre-Díez, \& López-Coronado, 2013). The 3,600 apps surveyed overwhelmingly deal with condition monitoring and information provision and none present any form of community member intervention coordinated with EMS as discussed in the current work. Most research that deals with emergency response through mHealth apps does so in the context of large scale disasters from the perspective of emergency case management (Gill, Alam, \& Eustace, 2015) rather than individual participation.

To move beyond information sharing, patient monitoring, behaviour modification, and peer influencing and harness the social network for actual emergency intervention we apply a flow model (Durugbo et al., 2013) to study community roles and participation, and identify supervisory control and health policy issues which influence the nature of participation.

In the remainder of this paper we map out the potential, challenges, and risks, explain the nature of emergency response community information flow and medication flow, and present the example of such an emergency response community for anaphylaxis. We begin with a description of information flow and medication flow in the ERC ecosystem. We then provide an illustrative example showing how an ERC can address the community of chronic allergy sufferers at risk of anaphylaxis and focus upon the nature and challenges of participation. We summarize a number of significant issues that must be addressed and conclude with an agenda for future research. 




Fig. 1. EMS View of Anaphylaxis Alert Scenario

\section{Design and Flow of Emergency Response Participation}

Modelling workflow and information flow is an established methodology for studying medical scenarios, such as chronic patient care (Unertl et al., 2009). This approach is based on the soft systems methodology (Checkland, 2000; Mingers, 2000) which is well documented as a methodology for process innovation (Presley, Sarkis, \& Liles, 2000). The soft systems methodology is seen as a practical way to operationalize Vickers concept of social process as appreciative system (Stowell, 2013). The process, as applied in the design of an ERC for anaphylaxis, incorporated iteratively presenting the system design for feedback to 18 medical professionals across the fields of Emergency Medicine (8), Allergy and Clinical Immunology (4), Pharmacology (4) and Public Health (4).

Observe the scenario emergency shown in Figure 1. Here we present a map superimposed with internal ERC member data for a defined geographical area and treatment range (referred to as the EMS view as this information is hidden from individual members). In this scenario there are 6 registered patients, E1 through E6, carrying some form of epinephrine injection or alternative treatment in the observed area, with a 7 th and 8th observed members (A1 and A2) carrying asthma inhalers. This scenario was developed through the insights gained from our information flow modelling process.

\subsection{Information flow and medication flow}

Information flow models (Durugbo et al., 2013) model the transfer of information between entities in a bounded organization or decision environment. We use information flow modelling (Figure 2) to depict the interactions between the main entities in the ERC ecosystem and identify design and health policy issues. These entities include: (a) patient or community member; (b) authorizing medical professional; (c) EMS centre; and (d) the ERC server. Generically we refer to all patients with registered medications as 'members' of their emergency response community. Entities can adopt multiple roles without changing identity so that, the 'patient' entity can be, at alternate times, a 'registered member' who has simply registered with the system; a 'requesting member' who has initiated an alert; 'a responding 
member' who is answering an alert call. The insights gained from the flow model served as the basis for the overall system architecture and application design.

We illustrate through a specific emergency response scenario resulting from the implementation of an ERC for anaphylaxis. The ERC system design is based on the analysis of information, supervisory, and medication flows.

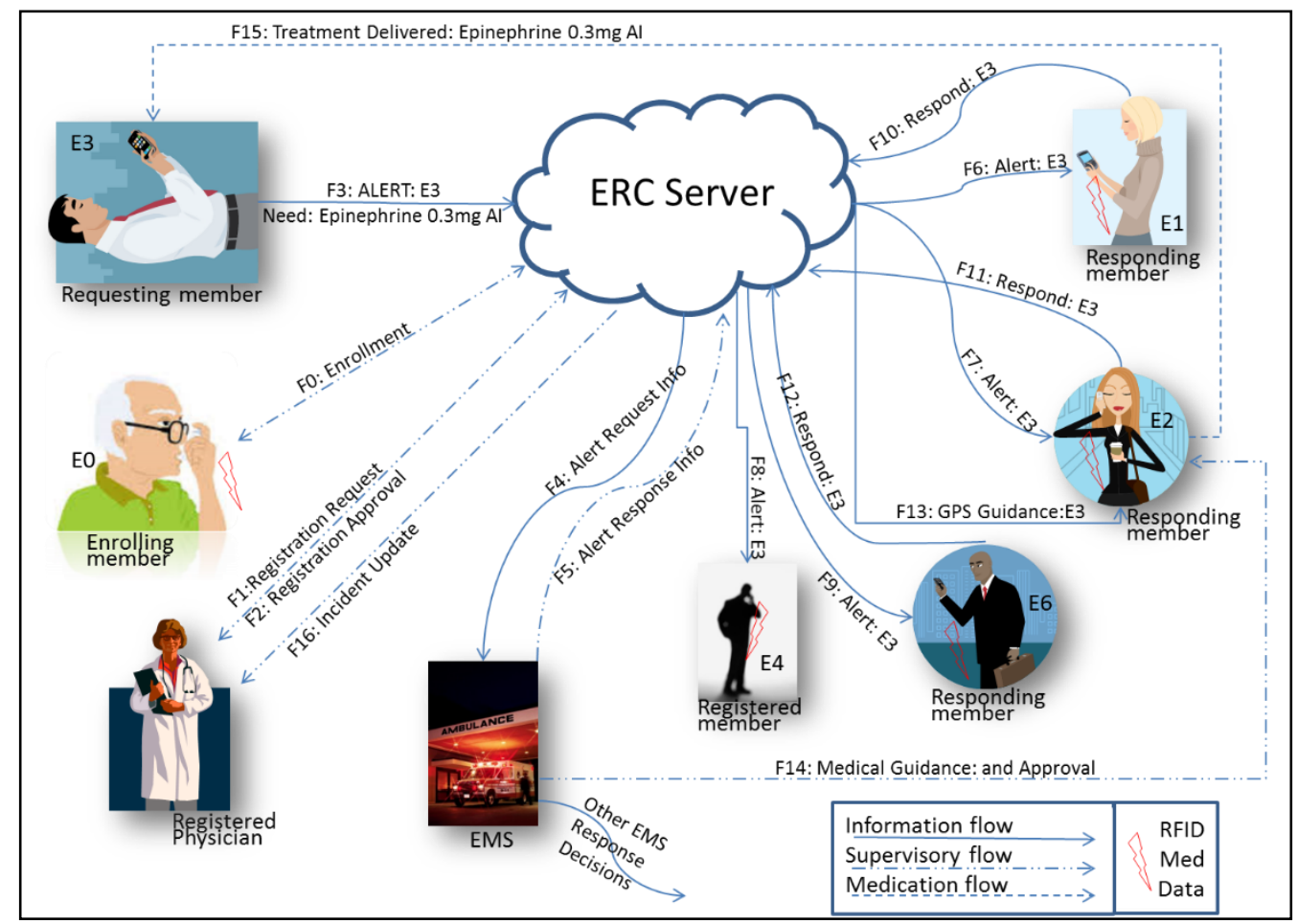

Fig. 2. Participation in the ERC Ecosystem: Information flow, Supervisory flow, and Medication flow.

Following the scenario introduced above, E3 experiences an allergic reaction with anaphylactic symptoms and realizes that his injector is missing. He initiates an ERC alert on his smartphone (Figure 3, panel A). This alert is immediately transmitted, via the ERC server, to each of the other members with registered compatible medication in the valid alert range. Concurrently, an EMS alert is initiated enabling EMS to view the medications registered to E3 and all those responding to his call. Alert notifications (Figure 3, Panel B) are then sent to E1, E2, E4, and E6 (with E5 determined to be out of effective range). Upon receipt of the alert, E1, E2, and E6 all indicate that they are responding (E4 does not reply) and receive guidance (Figure 3, Panel C). E2 reaches the distressed E3 first, notes that approval has been sent by EMS (as indicated by the green checkmark in the app) and administers her epinephrine to E3. 


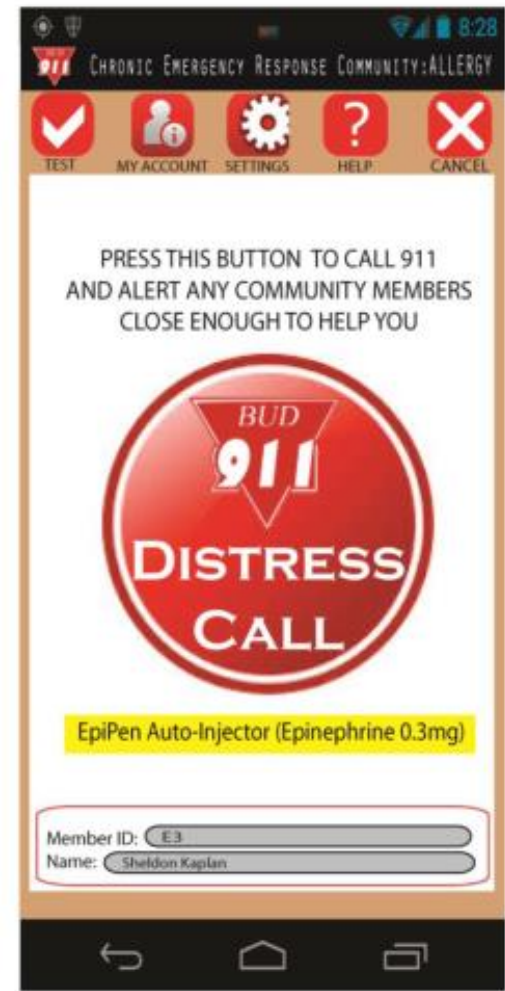

Panel A

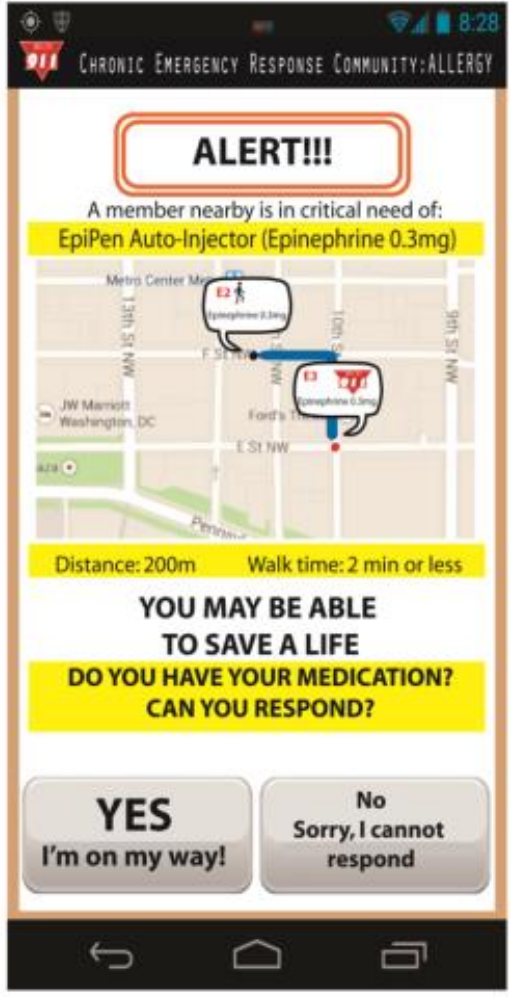

Panel B

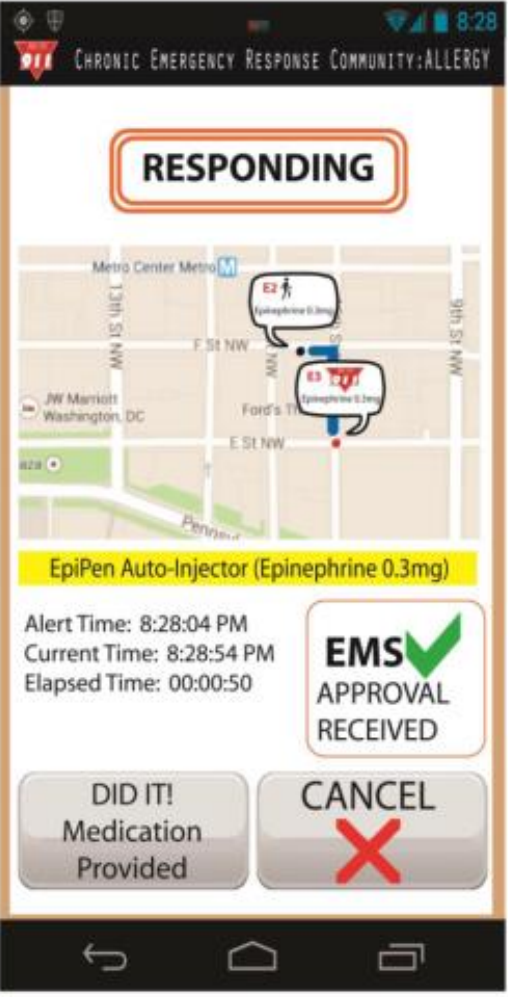

Panel C

Fig. 3. ERC mobile application screens

\subsection{Information flow and medication flow}

A flow model (Figure 2) was used to map out the different forms of participation and roles of participants that emerged from our discussions with the expert pool of medical professionals. Participants include:

Member - who at different life-cycle points can be:

(a) enrolling (awaiting approval); (b) in distress/alerting; (c) (un)available; and (d) responding;

Physician - whose initial participation is required to approve patient membership in the appropriate community and is updated whenever a supervised member is involved in an ERC event;

$E M S$ - which serves a supervisory role in approving responding member participation upon event occurrence;

The flows shown in Figure 2 are labelled Fo through F16. Table 2 presents details and significance of the main information flows. 


\begin{tabular}{|l|l|l|l|}
\hline F\# & From & To & Description \\
\hline Fo & $\begin{array}{l}\text { Enrolling } \\
\text { Member }\end{array}$ & ERC Cloud & $\begin{array}{l}\text { Community Enrollment and Medication Registration; } \\
\text { Prescription data and medication details. }\end{array}$ \\
\hline F1 & ERC Cloud & Physician & Request confirmation of patient details and prescription. \\
\hline F2 & $\begin{array}{l}\text { Primary } \\
\text { Physician }\end{array}$ & ERC Cloud & $\begin{array}{l}\text { Confirmation of patient details and prescription at time of } \\
\text { registration. }\end{array}$ \\
\hline F3 & $\begin{array}{l}\text { Member in } \\
\text { distress }\end{array}$ & ERC Cloud & $\begin{array}{l}\text { Emergency situation; Urgent need of critical medication; } \\
\text { Inform local EMS. }\end{array}$ \\
\hline F4 & ERC Cloud & $\begin{array}{l}\text { EMS } \\
\text { Central }\end{array}$ & $\begin{array}{l}\text { Condition and script data for Member in distress; Script data } \\
\text { and proximity for compatible members in range. }\end{array}$ \\
\hline F5 & EMS Central & ERC Cloud & $\begin{array}{l}\text { Expert EMS medical confirmation of recommended med } \\
\text { sources in range. }\end{array}$ \\
\hline $\begin{array}{l}\text { F6- } \\
\text { F9 }\end{array}$ & ERC Cloud & Members & $\begin{array}{l}\text { Member in distress is within range and compatible } \\
\text { medication detected; Requesting action. }\end{array}$ \\
\hline $\begin{array}{l}\text { F10- } \\
\text { F12 }\end{array}$ & $\begin{array}{l}\text { Available } \\
\text { Members }\end{array}$ & ERC Cloud & $\begin{array}{l}\text { Medication is available and willing to act; Requesting } \\
\text { guidance and confirmation. }\end{array}$ \\
\hline F13 & ERC Cloud & $\begin{array}{l}\text { Responding } \\
\text { Members }\end{array}$ & Tracking and guidance to arrive at member in distress. \\
\hline F14 & EMS Central & $\begin{array}{l}\text { Responding } \\
\text { Member }\end{array}$ & $\begin{array}{l}\text { Verification and confirmation of medication suitability by } \\
\text { EMS physician. }\end{array}$ \\
\hline F15 & $\begin{array}{l}\text { Responding } \\
\text { Member }\end{array}$ & $\begin{array}{l}\text { Member in } \\
\text { Distress }\end{array}$ & Physical delivery of medication. \\
\hline F16 & ERC Cloud & $\begin{array}{l}\text { Primary } \\
\text { Physician }\end{array}$ & Post-incident report of alert and response. \\
\hline
\end{tabular}

Table 1. Key Flow Summary

\subsection{From GPS Social Navigation technologies to ERCs}

The ability to track large numbers of participants across broad geographic regions, including assessments of speed and probable mode of transportation, has been established through recent developments in social navigation systems such as Google's Waze (www.waze.com /about) and Apple's Route Rating (Fino, 2011). These systems treat the driver's smartphone as a proxy for car location and movement thereby deriving traffic characteristics and even the existence of new roads not previously mapped. With Waze activated, the location and movement of millions of participants is steadily transmitted to a server which continually reassesses traffic conditions and shares new routing recommendations with all participants in the relevant geographic area (Disatnik, Shmuelevitz, \& Levine, 2011). Similarly, ERC applications are able to treat the smartphone as a proxy for the location of specific medicines borne by members as per their registration. As this information is continually transmitted to the ERC server by the ERC application installed on each member's smartphone, we are able to determine in real-time which community members are within reach of a member in distress when an alert is initiated.

\section{Discussion}

The result of the anaphylaxis ERC design process highlights both immense potential and system risks. The patient safety and drug regulatory issues that are not dealt with in 'information sharing' communities lead us to a series of supervisory and safety considerations. By mapping the information, medication, and supervisory flows a robust ecosystem emerges which can serve as the basis for changing emergency response activities. In this section we address a number of regulatory, safety and privacy issues before addressing the core questions related to participation.

\subsection{Regulatory, Safety, Legal, and Privacy Challenges}

In all chronic emergency response scenarios the ERC approach includes and comes in addition to immediate EMS contact and dispatch. We advocate training in auto-injector use for all 
community members and note that recognition in the importance of such training is growing (Kastner et al., 2010; Manivannan et al., 2014).

Regulatory issues related to prescription drug sharing; human risks related to unsuitable or improperly administered treatments; liability issues related to adverse effects; privacy concerns related to the voluntary disclosure of medical needs; all must be addressed. Sharing prescription drugs is dangerous, illegal in most jurisdictions, and the centre of much research and many prevention efforts (Goldsworthy, Schwartz, \& Mayhorn, 2008). To be clear, while there is the potential to misuse and abuse, a manifold potential for drug abuse exists in a variety of social networking environments (Hanson, Cannon, Burton, \& Giraud-Carrier, 2013). Rather than promoting misuse, the ERC ecosystem enables identification, tracking, study, professional guidance and follow-up.

While this article is not a source of legal advice or guidance regarding the sharing of prescription medications, in order to advance the research in this area herein are some initial findings regarding good Samaritan laws and medication provision in emergency situations. The analysis of each jurisdiction needs to be done separately, and must address the distinct questions of (a) legality of providing the medication which may be in violation of controlled drug legislation; and (b) immunity from prosecution in the event of a negative results which is commonly address by Good Samaritan laws. We bring two illustrative examples.

According to British Regulation 238 of the Human Medicines Regulations 2012, certain prescription-only medicines can be administered by anyone for the purpose of saving life in an emergency. This includes adrenaline for intramuscular use in anaphylaxis (MHRA, 2014). In the U.K. (England and Wales) actions of volunteer Samaritans are protected under the Social Action, Responsibility and Heroism (SARAH) Act (U.K., 2015, sec. 3).

In the United States legislation varies according to State. For example, in May 2015 Colorado passed Bill 15-1232 allowing any person to "...provide an epinephrine auto-injector to an individual believed in good faith to be experiencing anaphylaxis or to provide an epinephrine auto-injector to a family member, friend, colleague, caregiver, or person with a similar relationship with the individual" and further extends immunity from prosecution for in the event of adverse effects to "an individual who provides or administers an epinephrine autoinjector" provided it was done in good faith and devoid of negligence. (Colorado State Legislature, 2015).

Each chronic condition and treatment response requires in-depth study to assess the risks and benefits. Indirect effects such as increasing the level of patients filling and being in possession of their own required prescriptions (Johnson \& Parker, 2006) must also be studied. Certain treatment areas may be determined to be off-limits due to unacceptable risks. For example, sharing insulin pens and cartridges is against the explicit policies of the CDC (2012), and FDA (2013), described by the former as a "never event" which can result in transmission of hepatitis viruses, HIV, or other blood-borne pathogens - yet perhaps it would be considered an acceptable risk if the alternative is the onset of diabetic shock. Recent advances related to the availability of epinephrine in schools, may provide guidance as to the broader potential of ERCs (Madigan \& Hasbrouck, 2012) in this treatment area.

Privacy issues must be considered. Members of an ERC will have voluntarily put their use of a given medical treatment into the public sphere. This increases the ability of a third party to become aware of an individual's medical needs and make determinations regarding his or her medical condition. This issue is already being considered by sites such as PatientsLikeMe (Wicks et al., 2010). Each ERC member retains complete anonymity from other members up until such time as he or she responds to an alert or initiates one. The primary questions to be addressed here are: is the privacy being willingly sacrificed, and is the individual afforded a benefit worthy of that sacrifice (Shortliffe \& Cimino, 2006). In an ERC the answer to both questions appears to be a resounding 'yes' - nonetheless this area warrants further study. 


\subsection{Focusing on specific chronic conditions}

The decision to address anaphylaxis and asthma as the first two treatment areas was made based on their high prevalence and narrow treatment ranges. Similar characteristics can be found in use of glucose tablets to treat hypoglycaemia for diabetes which will be the subject of future research and development efforts. Each condition requires independent assessment of its suitability to our approach.

\subsection{Challenges to Participation}

In the study of crowd behaviour, an accepted definition of a crowd is that of a large group of individuals in the same physical environment, sharing a common goal. Crowd members are identified by the interests, attitudes, abilities and/or personal characteristics they have in common. Over time these common attributes provide a guide for action that conforms to their common social identification, but may not conform to individuals' self-identity when they are alone or in a small group (Musse \& Thalmann, 1997; Reicher, 2001; Roloff, 1981). In the study of internet-based crowdsourcing (Schenk \& Guittard, 2009; Surowiecki, 2004) a crowd can be defined as a large set of anonymous individuals that might not be individually identified, who work on a shared or given subtask via an internet platform. In the context of mHealth, a crowd may be formed by individuals joined together through the social network community supported by a medical app. When one community member requires assistance from another the task is accomplished by a single member drawn from the crowd who provides the necessary response - not by the crowd as a whole. The effectiveness of such mHealth apps depends on the response of individual members and their willingness to participate in a task demanding physical intervention when the responsibility of completion falls upon a single person rather than the crowd. This points us to studies that discuss crowd behaviour during actual emergencies in which a single person is in distress, and the theory of diffused responsibility (DR).

Crowd responses to Single Person Emergencies (SPE) has been investigated in the canonical work by Latane and Darley (1970). Bothered by recurrent incidents in which dozens of bystanders did nothing to help, they studied bystanders' motivations and actions during emergencies to reveal the effect of diffused responsibility. The doctrine of diffused responsibility holds that even if a person has noticed an event and defined it as an emergency, the mere knowledge of other witnessing bystanders can make him less likely to intervene (Darley \& Latane, 1968; Latane \& Darley, 1970). DR, however, does not explain strangers' behaviour regarding a distressed individual that share something in common with them, such as the same chronic illness or medication.

While a moral obligation to respond may exist, in absence of a legal obligation it is important to understand what might motivate community members to respond. For that we turn to the theory of Shared Identity. Piliavin, Rodin \& Piliavin (1969) investigated the effect of several variables on helping behaviour to reveal that bystanders are more likely to help if the victim was a member of their own racial group. The identity shared between the victim and the bystander leads to mutual aid that counteracted the effect of diffused responsibility due to perceptions of similarity and increased feelings of responsibility for welfare of others (Batson, 1987; Batson \& Ahmad, 2009; Coke, Daniel, \& McDavis, 1978; Dovidio, Piliavin, Gaertner, Schroeder, \& Clark III, 1991; J. A. Piliavin, 2009; Snyder \& Dwyer, 2012; Stotland, 1969). Shared identity (SI) goes beyond social classification to include factors ranging from sports team affiliations (Levine, Prosser, Evans, \& Reicher, 2005) to the identity shared between chronically ill patients (Brownstein, Brownstein, Williams, Wicks, \& Heywood, 2009; Frost \& Massagli, 2008; Stürmer, Snyder, \& Omoto, 2005). Shostack \& Fox (2012) explored the presence of a collective identity among people with epilepsy discovering strong evidence of group identity expressed as an expectation that people with epilepsy will help each other. Based on the above theoretical background we believe that the participation behaviour in mHealth emergency response situations will follow a hybrid behavioural model in which these conflicting impulses moderate. 


\subsection{Future Research Directions}

There are many risk, effectiveness, policy, and regulatory questions to be addressed. Studying both the request and response behaviours of community members and monitoring and studying the clinical results of interactions facilitated by ERC applications need to be at the forefront of our efforts. We present a number of the questions being dealt with in ongoing and future research. What percentage of participants will respond to community-member requests for emergency assistance when they believe that they can help save a life and what levels of response are required to be effective? How willing are participants to request and accept emergency assistance from a previously unknown responding community member when in distress? Will knowing they have the potential to help someone in distress increase member adherence levels and thus increase the potential for self-administration in times of need? (Johnson \& Parker, 2006). Conversely, will a free-rider phenomenon lower medication carrying amongst members who believe they can rely on a community member to come to their rescue? How might effective response radii differ as impacted by medical condition, medication match, transportation mode, member density, estimated time of arrive (ETA), and other relevant variables? How must legal frameworks (such as good Samaritan laws (Pardun, 1998)) and regulatory restrictions be modified to support participation in ERCs?

These are a number of the challenges being addressed as we move forward in the development and testing of Emergency Response Communities. In particular, user adaption and the correct strategies to engage with different user communities, is of particular importance in considering participatory medicine. Studies such as (Beaudry \& Pinsonneault, 2005) provide suitable strategies on which to base this future research.

\section{Conclusion}

Our approach to the use of social networks for emergency response presents a new conceptualization of 'social medicine' and raises new questions regarding the nature of participation. We have all heard, or asked, some form of the question: "I have a headache - do you have an aspirin?" We've asked colleagues, flight attendants, teachers, cab drivers - and have offered the same when asked. The archetypal question being asked and answered in our conceptualization of social medicine is "Do you have an aspirin?" where "aspirin" is replaced with a critical life-saving treatment and "you" is replaced with millions of people, any one of whom may be carrying such a treatment nearby at any given time. As the prevalence of chronic conditions continues to rise (Gerteis et al., 2014; Goodman, Posner, Huang, Parekh, \& Koh, 2013), by creating emergency response communities around chronic conditions such as acute allergies, asthma, diabetes, or heart disease, we have the ability to reshape society's response to individuals in medical distress - by reshaping the response of individuals in our society. Emergency medicine presents medical and economic challenges, and recognized trade-offs when an individual is in need of immediate intervention and traditional EMS support might not be able to respond immediately. As such it presents a new sub-domain for the study of participatory medicine and challenges that we have explored through the example of anaphylaxis.

\section{Acknowledgements}

The authors would like to thank Batya Schwartz for designing the ERC user interface and graphics.

\section{References}

Ahern, D. K., Woods, S. S., Lightowler, M. C., Finley, S. W., \& Houston, T. K. (2011). Promise of and Potential for Patient-Facing Technologies to Enable Meaningful Use. American Journal of Preventive Medicine, 4O(5, Supplement 2), S162-S172. http://doi.org/10.1016/j.amepre.2011.01.005 
Anderson, K., \& Emmerton, L. M. (2015). Contribution of mobile health applications to selfmanagement by consumers: review of published evidence. Australian Health Review. Retrieved from http://www.publish.csiro.au/?paper=AH15162

Batson, C. D. (1987). Prosocial motivation: Is it ever truly altruistic? Retrieved from http://psycnet.apa.org/psycinfo/1987-98851-002

Batson, C. D., \& Ahmad, N. Y. (2009). Using Empathy to Improve Intergroup Attitudes and Relations. Social Issues and Policy Review, 3(1), 141-177. http://doi.org/10.1111/j.17512409.2009.01013.x

Beaudry, A., \& Pinsonneault, A. (2005). Understanding user responses to information technology: A coping model of user adaptation. MIS Quarterly, 493-524.

Bilò, M. B., Cichocka-Jarosz, E., Pumphrey, R., Oude-Elberink, J. N., Lange, J., Jakob, T., ... Rueff, F. (2016). Self-medication of anaphylactic reactions due to Hymenoptera stingsan EAACI Task Force Consensus Statement. Allergy, 71(7), 931-943. http://doi.org/10.1111/all.12908

Brownstein, C. A., Brownstein, J. S., Williams, D. S., Wicks, P., \& Heywood, J. A. (2009). The power of social networking in medicine. Nature Biotechnology, 27(10), 888-890. http://doi.org/10.1038/nbt1009-888

Cappato, R., Curnis, A., Marzollo, P., Mascioli, G., Bordonali, T., Beretti, S., ... Cas, L. D. (2006). Prospective assessment of integrating the existing emergency medical system with automated external defibrillators fully operated by volunteers and laypersons for out-of-hospital cardiac arrest: the Brescia Early Defibrillation Study (BEDS). European Heart Journal, 27(5), 553-561. http://doi.org/10.1093/eurheartj/ehi654

CDC. (2012, January). CDC - Clinical Reminder: Insulin Pens - Injections Safety. Retrieved September 7, 2013, from http://www.cdc.gov/injectionsafety/clinicalreminders/insulin-pens.html

Checkland, P. (2000). Soft systems methodology: a thirty year retrospective. Systems Research and Behavioral Science, 17(S1), S11.

Chung, T., Gaudet, L., Vandenberghe, C., Couperthwaite, S., Sookram, S., Liss, K., ... Rowe, B. H. (2014). Pre-hospital management of anaphylaxis in one Canadian Urban Centre. Resuscitation. Retrieved from http://www.sciencedirect.com/science/article/pii/So300957214004729

Coke, J. S., Daniel, C., \& McDavis, K. (1978). Empathic mediation of helping: A two-stage model. Journal of Personality and Social Psychology, 36(7), 752-766. http://doi.org/10.1037/0022-3514.36.7.752

Colorado State Legislature. Concerning The Emergency Use Of Epinephrine Auto-Injectors By Authorized Entities, And, In Connection Therewith, Making An Appropriation, Pub. L. No. 15-1232 (2015). Retrieved from http://www.leg.state.co.us/clics/clics2015a/csl.nsf/fsbillcont3/B99CD6D4B75FFE848 7257DCFoo69CE28?Open\&file=1232_enr.pdf

Darley, J. M., \& Latane, B. (1968). Bystander intervention in emergencies: diffusion of responsibility. Journal of Personality and Social Psychology, 8(4p1), 377.

De Silva, D., Burstein, F., Stranieri, A., Williams, K., \& Rinehart, N. (2013). A participatory information management framework for patient centred care of autism spectrum disorder. In 24th Australasian Conference on Information Systems (ACIS) (pp. 1-11). RMIT University. Retrieved from https://researchbank.rmit.edu.au/view/rmit:161076

Disatnik, I., Shmuelevitz, Y., \& Levine, U. (2011, May 5). Device, system, and method of dynamic route guidance U.S. Patent Application No. 12/588,786. 
Dovidio, J. F., Piliavin, J. A., Gaertner, S. L., Schroeder, D. A., \& Clark III, R. D. (1991). The arousal: Cost-reward model and the process of intervention: A review of the evidence. In Prosocial behavior (pp. 86-118). Thousand Oaks, CA, US: Sage Publications, Inc.

Durugbo, C., Tiwari, A., \& Alcock, J. R. (2013). Modelling information flow for organisations: A review of approaches and future challenges. International Journal of Information Management, 33(3), 597-610. http://doi.org/10.1016/j.ijinfomgt.2013.01.009

Dyson, E. (2009). Why participatory medicine? Journal of Participatory Medicine. Retrieved from http://ojs.jopm.org/index.php/jpm/article/viewArticle/v1n1e1

Elsner, J., Meisen, P., Ewert, D., Schilberg, D., \& Jeschke, S. (2014). Prescient Profiling-AI driven Volunteer Selection within a Volunteer Notification System. In eTELEMED 2014, The Sixth International Conference on eHealth, Telemedicine, and Social Medicine (pp. 94-98). Retrieved from http://www.thinkmind.org/index.php?view=article\&articleid=etelemed_2014_5_20_ 40036

Elsner, J., Meisen, P., Thelen, S., Schilberg, D., \& Jeschke, S. (2013). EMuRgency-A Basic Concept for an AI Driven Volunteer Notification System for Integrating Laypersons into Emergency Medical Services. International Journal On Advances in Life Sciences, 5(3 and 4), 223-236.

Elsner, J., Schneiders, M.-T., Haberstroh, M., Schilberg, D., \& Jeschke, S. (2013). An Introduction to a Transnational Volunteer Notification System Providing Cardiopulmonary Resuscitation for Victims Suffering a Sudden Cardiac Arrest. In e TEL EMED 2013, The Fifth International Conference on eHealth, Telemedicine, and Social Medicine (pp. 59-64). Retrieved from http://www.thinkmind.org/index.php?view=article\&articleid=etelemed_2013_3_10_ 40119

FDA. (2013, August). Information for Healthcare Professionals: Risk of Transmission of Blood-borne Pathogens from Shared Use of Insulin Pens [WebContent]. Retrieved September 7, 2013, from http://www.fda.gov/Drugs/DrugSafety/PostmarketDrugSafetyInformationforPatients andProviders/DrugSafetyInformationforHeathcareProfessionals/ucm133352.htm

Fino, J. S. (2015) User-specified route rating and alerts. U.S. Patent 8,977,498, issued March 10, 2015 .

Folke, F., Lippert, F. K., Nielsen, S. L., Gislason, G. H., Hansen, M. L., Schramm, T. K., ... others. (2009). Location of cardiac arrest in a city center strategic placement of automated external defibrillators in public locations. Circulation, 12O(6), 510-517.

Frost, J. H., \& Massagli, M. P. (2008). Social Uses of Personal Health Information Within PatientsLikeMe, an Online Patient Community: What Can Happen When Patients Have Access to One Another's Data. Journal of Medical Internet Research, 1O(3), e15. http://doi.org/10.2196/jmir.1053

Gerteis, J., Izrael, D., Deitz, D., LeRoy, L., Ricciardi, R., Miller, T., \& Basu, J. (2014). Multiple chronic conditions chartbook. Rockville, MD: Agency for Healthcare Research and Quality (AHRQ) Publications.

Gill, A. Q., Alam, S. L., \& Eustace, J. (2015). Social Architecture: An Emergency Management Case Study. Australasian Journal of Information Systems, 19(0). http://doi.org/10.3127/ajis.v19io.979

Gold, J., Pedrana, A. E., Stoove, M. A., Chang, S., Howard, S., Asselin, J., ... Hellard, M. E. (2012). Developing Health Promotion Interventions on Social Networking Sites: Recommendations from The FaceSpace Project. Journal of Medical Internet Research, 14(1), e30. http://doi.org/10.2196/jmir.1875 
Goldsworthy, R. C., Schwartz, N. C., \& Mayhorn, C. B. (2008). Beyond Abuse and Exposure: Framing the Impact of Prescription-Medication Sharing. American Journal of Public Health, 98(6), 1115-1121. http://doi.org/10.2105/AJPH.2007.123257

Goodman, R. A., Posner, S. F., Huang, E. S., Parekh, A. K., \& Koh, H. K. (2013). Defining and Measuring Chronic Conditions: Imperatives for Research, Policy, Program, and Practice. Preventing Chronic Disease, 10. http://doi.org/10.5888/pcd10.120239

Griffiths, F., Cave, J., Boardman, F., Ren, J., Pawlikowska, T., Ball, R., ... Cohen, A. (2012). Social networks - The future for health care delivery. Social Science \& Medicine, 75(12), 2233-2241. http://doi.org/10.1016/j.socscimed.2012.08.023

Groh, W. J., Birnbaum, A., Barry, A., Anton, A., Mann, N. C., Peberdy, M. A., ... Mosesso Jr., V. N. (2007). Characteristics of volunteers responding to emergencies in the Public Access Defibrillation Trial. Resuscitation, 72(2), 193-199. http://doi.org/10.1016/j.resuscitation.2006.06.036

Hanson, C. L., Cannon, B., Burton, S., \& Giraud-Carrier, C. (2013). An Exploration of Social Circles and Prescription Drug Abuse Through Twitter. Journal of Medical Internet Research, 15(9), e189. http://doi.org/10.2196/jmir.2741

Hibberd, B. J., \& Evatt, A. (2004). Mapping information flows: A practical guide. The Information Management Journal, 38(1), 58-64.

Hood, L., \& Flores, M. (2012). A personal view on systems medicine and the emergence of proactive $\mathrm{P} 4$ medicine: predictive, preventive, personalized and participatory. New Biotechnology, 29(6), 613-624. http://doi.org/10.1016/j.nbt.2012.03.004

Johnson, D. (2014, July 24). DHF Partners with HelpAround in an Effort to Connect People Touched by Diabetes | Diabetes Hands Foundation. Retrieved from http://diabeteshandsfoundation.org/dhf-and-helparound-work-together-to-bringpeople-touched-by-diabetes-closer/

Johnson, T. L., \& Parker, A. L. (2006). Rates of retrieval of self-injectable epinephrine prescriptions: a descriptive report. Annals of Allergy, Asthma \& Immunology: Official Publication of the American College of Allergy, Asthma, \& Immunology, 97(5), 694697. http://doi.org/10.1016/S1081-1206(10)61102-7

Kastner, M., Harada, L., \& Waserman, S. (2010). Gaps in anaphylaxis management at the level of physicians, patients, and the community: a systematic review of the literature. Allergy, 65(4), 435-444. http://doi.org/10.1111/j.1398-9995.2009.02294.x

Klasnja, P., \& Pratt, W. (2012). Healthcare in the pocket: Mapping the space of mobile-phone health interventions. Journal of Biomedical Informatics, 45(1), 184-198. http://doi.org/10.1016/j.jbi.2011.08.017

Latane, B., \& Darley, J. M. (1970). The unresponsive bystander: Why doesn't he help? Prentice-Hall.

Levine, M., Prosser, A., Evans, D., \& Reicher, S. (2005). Identity and Emergency Intervention: How Social Group Membership and Inclusiveness of Group Boundaries Shape Helping Behavior. Personality and Social Psychology Bulletin, 31(4), 443-453. http://doi.org/10.1177/0146167204271651

Madigan, L., \& Hasbrouck, L. (2012, August 13). Emergency Epinephrine Act (Public Act 970361) Physician's Toolkit. Illinois Department of Public Health.

Maio, R. F., Garrison, H. G., Spaite, D. W., Desmond, J. S., Gregor, M. A., Cayten, C., ... others. (1999). Emergency medical services outcomes project I (EMSOP I): prioritizing conditions for outcomes research. Annals of Emergency Medicine, 33(4), 423-432.

Malvey, D., \& Slovensky, D. J. (2014). mHealth: transforming healthcare. Springer. Retrieved from 
https://books.google.co.nz/books?hl=en\&lr=\&id=f2YgBAAAQBAJ\&oi=fnd\&pg=PP5\&d $\mathrm{q}=$ Malvey $+\mathrm{D},+$ Slovensky+DJ.+mHealth:+transforming + healthcare.+New+York:+Spri nger,+2014.\&ots=wWiYoKRGu-\&sig=FUtgdfHfbnUizMIIZ1xpTYxvR4U

Manivannan, V., Hess, E. P., Bellamkonda, V. R., Nestler, D. M., Bellolio, M. F., Hagan, J. B., ... Campbell, R. L. (2014). A Multifaceted Intervention for Patients With Anaphylaxis Increases Epinephrine Use in Adult Emergency Department. The Journal of Allergy and Clinical Immunology: In Practice, 2(3), 294-299.e1. http://doi.org/10.1016/j.jaip.2013.11.009

Marshall, A. H., Cairns, K. J., Kee, F., Moore, M. J., Hamilton, A. J., \& Adgey, A. (2006). A Monte Carlo simulation model to assess volunteer response times in a public access defibrillation scheme in Northern Ireland. In Computer-Based Medical Systems, 2006. CBMS 2006. 19th IEEE International Symposium on (pp. 783-788). IEEE. Retrieved from http://ieeexplore.ieee.org/document/1647666/

Martínez-Pérez, B., de la Torre-Díez, I., \& López-Coronado, M. (2013). Mobile Health Applications for the Most Prevalent Conditions by the World Health Organization: Review and Analysis. Journal of Medical Internet Research, 15(6), e120. http://doi.org/10.2196/jmir.2600

McKemmish, S., Burstein, F., Faulkhead, S., Fisher, J., Gilliland, A. J., McLoughlin, I., \& Wilson, R. (2012). Working with communities: Community partnership research in information technology, management and systems. Information, Communication \& Society, 15(7), 985-990.

Merchant, R. M., Asch, D. A., Hershey, J. C., Griffis, H. M., Hill, S., Saynisch, O., ... others. (2013). A crowdsourcing innovation challenge to locate and map automated external defibrillators. Circulation: Cardiovascular Quality and Outcomes, 6(2), 229-236.

MHRA. (2014). Administration of injectable medicines for the purpose of saving life in an emergency. $\quad$ Retrieved September 2, 2013, from http://www.mhra.gov.uk/Howweregulate/Medicines/Availabilityprescribingsellingand supplyingofmedicines/ExemptionsfromMedicinesActrestrictions/Administrationofinje ctablemedicinesforthepurposeofsavinglifeinanemergency/index.htm

Mingers, J. (2000). An idea ahead of its time: the history and development of soft systems methodology. Systemic Practice and Action Research, 13(6), 733-755.

Musse, S. R., \& Thalmann, D. (1997). A model of human crowd behavior: Group interrelationship and collision detection analysis. Springer. Retrieved from http://link.springer.com/chapter/10.1007/978-3-7091-6874-5_3

Pardun, J. T. (1998). Good Samaritan Laws: A Global Perspective. Loyola of Los Angeles International and Comparative Law Journal, 2O, 591.

Parmanto, B., Pramana, G., Yu, D. X., Fairman, A. D., Dicianno, B. E., \& McCue, M. P. (2013). iMHere: A Novel mHealth System for Supporting Self-Care in Management of Complex and Chronic Conditions. JMIR Mhealth and Uhealth, 1(2), e10. http://doi.org/10.2196/mhealth.2391

Peberdy, M. A., Ottingham, L. V., Groh, W. J., Hedges, J., Terndrup, T. E., Pirrallo, R. G., ... Sehra, R. (2006). Adverse events associated with lay emergency response programs: The public access defibrillation trial experience. Resuscitation, 70(1), 59-65. http://doi.org/10.1016/j.resuscitation.2005.10.030

Piliavin, I. M., Rodin, J., \& Allyn Piliavin, J. (1969). Good samaritanism: An underground phenomenon? Journal of Personality and Social Psychology, 13, 289-299.

Piliavin, J. A. (2009). Altruism and helping: the evolution of a field: The 2008 Cooley-Mead Presentation. Social Psychology Quarterly, 72(3). http://doi.org/10.1177/019027250907200305 
Presley, A., Sarkis, J., \& Liles, D. H. (2000). A soft-systems methodology approach for product and process innovation. IEEE Transactions on Engineering Management, 47(3), 379392.

Rea, T., Blackwood, J., Damon, S., Phelps, R., \& Eisenberg, M. (2011). A link between emergency dispatch and public access AEDs: potential implications for early defibrillation. Resuscitation, 82(8), 995-998.

Reicher, S. (2001). The psychology of crowd dynamics. Blackwell Handbook of Social Psychology: Group Processes, 182-208.

Roloff, M. E. (1981). Interpersonal communication: The social exchange approach. Sage Publications Beverly Hills, CA. Retrieved from http://library.wur.nl/WebQuery/clc/163266

Sabaté, E. (2003). Adherence to Long-term Therapies: Evidence for Action. World Health Organization.

Sakai, T., Iwami, T., Kitamura, T., Nishiyama, C., Kawamura, T., Kajino, K., ... others. (2011). Effectiveness of the new "Mobile AED Map"to find and retrieve an AED: A randomised controlled trial. Resuscitation, 82(1), 69-73.

Schenk, E., \& Guittard, C. (2009). Crowdsourcing: What can be Outsourced to the Crowd, and Why? Retrieved from http://halshs.archives-ouvertes.fr/halshs-00439256/

Schwartz, D. G., Bellou, A., Garcia-Castrillo, L., Muraro, A., \& Papadopoulos, N. G. (2014). Towards chronic emergency response communities for anaphylaxis. In 2014 IEEE 15th International Conference on Information Reuse and Integration (IRI) (pp. 98-103). https://doi.org/10.1109/IRI.2014.7051878

Shortliffe, E. H., \& Cimino, J. J. (2006). Biomedical Informatics: Computer Applications in Health Care and Biomedicine. Springer.

Shostak, S., \& Fox, N. S. (2012). Forgetting and remembering epilepsy: collective memory and the experience of illness. Sociology of Health \& Illness, 34(3), 362-378.

Shrank, W. H., Choudhry, N. K., Swanton, K., \& et al. (2011). Variations in structure and content of online social networks for patients with diabetes. Archives of Internal Medicine, 171(17), 1589-1591. http://doi.org/10.1001/archinternmed.2011.407

Simons, F. E. R., \& World Allergy Organization. (2009). Epinephrine auto-injectors: first-aid treatment still out of reach for many at risk of anaphylaxis in the community. Annals of Allergy, Asthma \& Immunology: Official Publication of the American College of Allergy, Asthma, \& Immunology, 102(5), 403-409. http://doi.org/10.1016/S10811206(10)60512-1

Smith, C. W., Graedon, J., \& Graedon, T. (2016). Editorial Policies. Retrieved May 1, 2016, from http://www.jopm.org/editorial-policies/\#focusAndScope

Snyder, M., \& Dwyer, P. C. (2012). Altruism and prosocial behavior. Handbook of Psychology, $5,467-486$.

Song, T. T., Worm, M., \& Lieberman, P. (2014). Anaphylaxis treatment: current barriers to adrenaline auto-injector use. Allergy. http://doi.org/10.1111/ all.12387.

Standards of Medical Care in Diabetes--2012. (2011). Diabetes Care, 35(Supplement_1), S11S63. http://doi.org/10.2337/dc12-s011

Stotland, E. (1969). Exploratory investigations of empathy. Advances in Experimental Social Psychology, 4, 271-314.

Stowell, F. (2013). The Appreciative Inquiry Method-A Suitable Candidate for Action Research? Systems Research and Behavioral Science, 3O(1), 15-30. 
Stürmer, S., Snyder, M., \& Omoto, A. M. (2005). Prosocial Emotions and Helping: The Moderating Role of Group Membership. Journal of Personality and Social Psychology, 88(3), 532-546. http://doi.org/10.1037/0022-3514.88.3.532

Surowiecki, J. (2004). The wisdom of crowds: Why the many are smarter and how collective wisdom shapes business, economies, societies, and nations, Doubleday.

Swan, M. (2009). Emerging patient-driven health care models: an examination of health social networks, consumer personalized medicine and quantified self-tracking. International Journal of Environmental Research and Public Health, 6(2), 492-525.

U.K. Social Action, Responsibility and Heroism Act 2015, § 3 (2015). Retrieved from http://www.legislation.gov.uk/ukpga/2015/3/introduction/enacted

Unertl, K. M., Weinger, M. B., Johnson, K. B., \& Lorenzi, N. M. (2009). Describing and modeling workflow and information flow in chronic disease care. Journal of the American Medical Informatics Association, 16(6), 826-836.

US Department of Health and Human Services. (2007). Expert Panel Report 3: Guidelines for the Diagnosis and Management of Asthma. Retrieved from http://www.nhlbi.nih.gov/guidelines/asthma/asthgdln.htm

van der Eijk, M., Faber, M. J., Aarts, J. W., Kremer, J. A., Munneke, M., \& Bloem, B. R. (2013). Using Online Health Communities to Deliver Patient-Centered Care to People With Chronic Conditions. Journal of Medical Internet Research, 15(6), e115. http://doi.org/10.2196/jmir.2476

Weitzman, E. R., Kelemen, S., Quinn, M., Eggleston, E. M., \& Mandl, K. D. (2013). Participatory surveillance of hypoglycemia and harms in an online social network. JAMA Internal Medicine, 173(5), 345-351. http://doi.org/10.1001/jamainternmed.2013.2512

Wicks, P., Massagli, M., Frost, J., Brownstein, C., Okun, S., Vaughan, T., ... Heywood, J. (2010). Sharing health data for better outcomes on PatientsLikeMe. Journal of Medical Internet Research, 12(2). http://doi.org/10.2196/jmir.1549

Copyright: (C) 2017 Schwartz, Bellou, Garcia-Castrillo, Muraro \& Papadopoulos. This is an open-access article distributed under the terms of the Creative Commons AttributionNonCommercial 3.0 Australia License, which permits non-commercial use, distribution, and reproduction in any medium, provided the original author and AJIS are credited.

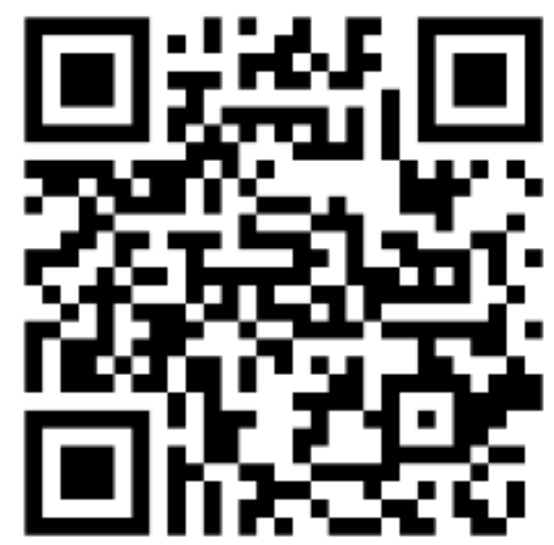

